\title{
AVALIAÇÕES MORFOFISIOLÓGICAS DO FEIJÃO PÉROLA IRRIGADO
}

\author{
Catariny Cabral Aleman ${ }^{1}$, Flávia Alessandra Mignacca ${ }^{2}$ \\ ${ }^{1}$ Universidade Federal de Viçosa - UFV, Departamento de Engenharia Agrícola, Viçosa, MG. ${ }^{2}$ Universidade do Oeste Paulista - \\ UNOESTE, Presidente Prudente, SP. E-mail: catariny@ufv.br
}

\section{RESUMO}

O objetivo deste trabalho foi avaliar as características morfofisiológicas do feijão Pérola submetido a diferentes lâminas de irrigação na região do Oeste Paulista. O experimento foi conduzido na cidade de Pirapozinho, São Paulo, utilizando vasos de $25 \times 32 \mathrm{~cm}$, em condições de campo, no período de março a maio. O delineamento experimental foi em blocos ao acaso, com seis lâminas de irrigação: 25\%, 50\%, 75\%, 100\%, 125\% e 150\% da evapotranspiração da cultura (ETc) e 5 repetições. Os parâmetros avaliados foram altura das plantas, massa seca de parte aérea, massa seca de raiz, número vagens por planta, peso de vagens, número de sementes por vagem, germinação das sementes e determinação do teor de prolina nas folhas. Os dados foram submetidos ao teste $\mathrm{F}$ e posteriormente ao teste Tukey para comparação de médias ao nível de probabilidade de $5 \%$. Observou-se que os resultados foram significativos para o peso de vagens, o número de grãos por vagem e teor de prolina. Concluiu-se que a lâmina de irrigação de $75 \%$ ETc resultou na maior produção de sementes. A lâmina de irrigação de $25 \%$ ETc promoveu déficit hídrico, indicado pela maior concentração de prolina nas folhas frescas.

Palavras-chave: estresse hídrico; Phaseolus vulgaris; produtividade.

\section{MORPHOPHISIOLOGICAL IRRIGATED PEARL BEAN REVIEWS}

\begin{abstract}
The aimed of this study was to evaluate the physical and physiological characteristics of the Pearl beans under different irrigation levels in Oeste Paulista region. The experiment was conducted in the city of Pirapozinho, Sao Paulo, using pots of $25 \times 32 \mathrm{~cm}$, under field conditions, from March to May. The experimental design was a randomized block with six depths of irrigation: 25\%, $50 \%, 75 \%, 100 \%, 125 \%$ and $150 \%$ crop evapotranspiration ( ETc ) and 5 replication. The parameters evaluated were plant height, shoot dry weight, root dry weight, number of pods per plant, pod weight, number of seeds per pod, seed germination and foliar proline. The data were analyzed using the $\mathrm{F}$ test and then the Tukey test for comparison of the probability level of $5 \%$. It was observed that the results were significant for the weight of the strings, the number of seeds per pod and the concentration of proline. It was concluded that the depth of irrigation of $75 \%$ ETc resulted in higher seed production. The irrigation of $25 \%$ ETC promoted water deficit, indicated by the higher concentration of proline in fresh leaves.
\end{abstract}

Keywords: hydric stress; Phaseolus vulgaris; productivity.

\section{INTRODUÇÃO}

O feijão comum (Phaseolus vulgaris L.) pertence à família Fabaceae e é originário do continente americano. $\mathrm{O}$ ciclo de desenvolvimento varia de 61 a 110 dias. 0 produto final da cultura é a semente, um dos alimentos básicos da nutrição da população brasileira (FARIAS et al., 2010).

$\mathrm{Na}$ maioria das regiões predomina a exploração do feijoeiro por pequenos agricultores e agricultura familiar, com uso reduzido de insumos e baixas produtividades. Segundo dados da CONAB (2013), considerando as três safras, estima-se que a área total de feijão poderá chegar a $3.333,4$ hectares, $8,4 \%$ maior que a safra passada. A produtividade média nacional é estimada em $13,2 \%$ acima da safra passada, totalizando $1.033 \mathrm{~kg} / \mathrm{ha}$, a produção deverá alcançar $3.444,1$ toneladas, $22,7 \%$ maior que a última safra.

O feijoeiro é extremamente sensível a situações extremas de estresse hídrico, ou seja, deficiência ou excesso de água (SILVA et al.; 2011). A duração, a frequência e a intensidade do estresse afetam a maioria dos processos metabólicos, interferindo diretamente no rendimento de grãos. A necessidade hídrica do feijoeiro varia de 300 a $500 \mathrm{~mm}$ por ciclo de desenvolvimento, podendo ser suprida de acordo com o regime de precipitações ou por meio de irrigações considerando a capacidade de 
armazenamento de água do solo (PAVANI et al., 2009, CARVALHO et al., 2014).

A agricultura irrigada é um dos setores que apresentam grande relevância quanto ao uso eficiente da água, já que em escala global é a atividade que consome $70 \%$ do total de água disponível (BEZERRA et al., 2012). A irrigação visa suprir as necessidades hídricas da planta considerando as condições climáticas e a disponibilidade de água no solo. Uma das práticas de manejo de irrigação é o cálculo da lâmina de irrigação em função da determinação da evapotranspiração da cultura (ETc). Esse parâmetro é determinado em função da evapotranspiração de referência (ETo) e do coeficiente de cultura, que integram alguns fatores como altura das plantas, relação culturasolo e a disponibilidade de água no solo (ALLEN et al., 1998; RIOS et al., 2011; ANDRADE et al., 2013).

Considerando a importância da determinação da quantidade de água adequada para tornar eficiente o uso deste recurso hídrico na produção do feijoeiro, o objetivo deste trabalho foi avaliar as características morfofisiológicas do feijão Pérola submetido a diferentes lâminas de irrigação na região do Oeste Paulista.

\section{MATERIAL E MÉTODOS}

O experimento foi conduzido em vasos instalados em condições de campo, na cidade de Pirapozinho, latitude: 22ㅇ 16' 31" S longitude: 51은
30' 31" W e altitude de 487 metros. O delineamento experimental foi em blocos ao acaso com 6 lâminas de irrigação e 5 repetições, totalizando 30 unidades experimentais. Os vasos com dimensões 25 de diâmetro $\times 32 \mathrm{~cm}$ de altura foram preparados utilizando solo classificado como Argissolo Vermelho - Amarelo, Eutrófico de textura arenosa/média (EMBRAPA, 1999). Foram utilizadas sementes de feijão Pérola (IPR 139, germinação: $85 \%$ e pureza: $98 \%$ ). A semeadura ocorreu 10 de março de 2013 e a colheita 20 de maio de 2013, resultando em um ciclo de 70 dias.

Os tratamentos foram constituídos por seis lâminas de irrigação: T1) 25\% (7,41 mm), T2) $50 \%(14,82 \mathrm{~mm})$, T3) $75 \%(22,22 \mathrm{~mm}), \mathrm{T} 4) 100 \%$ $(29,63 \mathrm{~mm})$, T5) $125 \%(37,04 \mathrm{~mm})$ e T6) $150 \%$ $(44,45 \mathrm{~mm})$ da evapotranspiração da cultura (ETc). As lâminas de irrigação foram determinadas a partir do balanço hídrico diário, através de dados obtidos do INMET (Instituto Nacional de Meteorologia). Foram utilizados o método FAO - Penman-Monteith (equação 1, 2, 3 e 4) para determinação da evapotranspiração de referência (ETo) e o coeficiente de cultura (kc) do feijão de 0,95 (FOLEGATTI, 2013), para determinação da evapotranspiração da cultura (equação 5).

A capacidade de armazenamento foi determinada de acordo com o modelo de Van Genuchten (1980), considerando a $\theta c c=29 \%$, $\theta p m p=16 \%$ e a profundidade efetiva do sistema radicular de $20 \mathrm{~cm}$.

$$
\begin{aligned}
& \text { ETo }=\underline{0,408 \cdot s .(R n-G)+\gamma \cdot 900 \cdot U_{2}\left[\frac{\text { es-ea }}{\mathrm{Td}+273}\right]} \\
& \mathrm{s}+\gamma \cdot\left(1+0,34 . \mathrm{U}_{2}\right) \\
& \mathrm{G}=0,38 .\left(\mathrm{T}_{\mathrm{d}}-\mathrm{T}_{3 \mathrm{~d}}\right)
\end{aligned}
$$

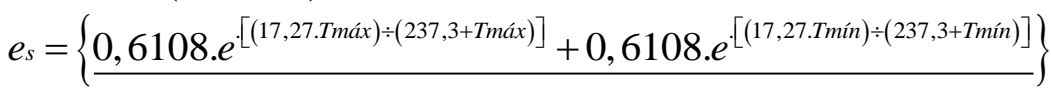

$$
\begin{aligned}
& 2 \\
& \mathrm{e}_{\mathrm{a}}=\left(\frac{\text { UR.es }}{100}\right) \\
& \mathrm{ETc}=\mathrm{ETo} \times \mathrm{kc}
\end{aligned}
$$

Sendo: $\mathrm{ETo}=$ evapotranpiração de referência $\left(\mathrm{mm} \mathrm{dia}{ }^{-1}\right) ; \mathrm{Rn}=$ radiação líquida total diária $\left(\mathrm{MJ} \mathrm{m} \mathrm{m}^{-2} \mathrm{dia}^{-1}\right) ; \mathrm{G}=$ fluxo total diário de calor no solo $\left(\mathrm{MJ} \mathrm{m}^{-2}\right.$ dia $^{-1}$ ) (equação 2$) ; \gamma=$ constante psicométrica $\left(0,063 \mathrm{kPa}^{\circ} \mathrm{C}^{-1}\right) ; \mathrm{T}_{\mathrm{d}}=$ temperatura média diária $\left({ }^{\circ} \mathrm{C}\right) ; \mathrm{U}_{2}=$ velocidade do vento $\left(\mathrm{m} \mathrm{s}^{-1}\right) ; \mathrm{e}_{\mathrm{s}}=$ pressão de saturação de vapor ( $\mathrm{kPa}$ ) (equação 3 ); $\mathrm{e}_{\mathrm{a}}=$ pressão parcial de vapor ( $\mathrm{kPa}$ ) (equação 4); $\mathrm{s}=$ declividade da curva de pressão de vapor $\left(\mathrm{kPa}{ }^{\circ} \mathrm{C}^{-1}\right)$; $\mathrm{ETc}=$ evapotranspiração da cultura ( $m \mathrm{~m} \mathrm{dia}^{-1}$ ) e kc=coeficiente de cultura (equação 5).

Os parâmetros avaliados foram altura das plantas, massa seca de parte aérea, massa seca de raiz, número vagens por planta, peso de vagens, número de sementes por vagem, 
germinação das sementes e determinação do teor de prolina nas folhas.

A germinação das sementes colhidas foi realizada em papel Germitest, acondicionado em germinador para grandes culturas à temperatura de $25^{\circ} \mathrm{C}$ constantes. Foi realizada leitura de germinação após 7 dias (NAKAGAWA, 1999).

A prolina foi extraída de folhas frescas coletadas no dia da colheita. Foi utilizado o método de Bates et al. (1973) modificado por Machado Neto et al. (2004). A curva padrão de prolina utilizou concentrações de 0 a $80 \mu \mathrm{L} \mathrm{mL}^{-1}$ de prolina estoque em ácido sulfosalícilico $3 \%$ e ninidrina ácida.

Os parâmetros avaliados foram submetidos ao teste $\mathrm{F}$ e a comparação de médias pelo teste de Tukey ao nível de significância de $5 \%$.

\section{RESULTADOS E DISCUSSÃO}

Tabela 1. Valores de $\mathrm{F}$ para os parâmetros avaliados no feijão Pérola irrigado com as lâminas de irrigação de $25,50,75,100,125$ e $150 \%$ ETc.

\begin{tabular}{lll}
\hline & $\mathrm{L}$ & C.V. $(\%)$ \\
\hline G.L. & 5 & - \\
Alt 1 & 0,7094 n.s. & 25,66 \\
Alt 2 & 0,1560 n.s. & 24,56 \\
Alt 3 & 0,5002 n.s. & 25,18 \\
Alt 4 & 0,5018 n.s. & 25,14 \\
Alt 5 & 1,5096 n.s & 22,38 \\
MSPA & 1,5806 n.s. & 20,91 \\
MSR & 0,7929 n.s. & 20,81 \\
PV & $2,7125 *$ & 26,68 \\
NV & 1,3635 n.s. & 26,73 \\
NS & $4,7524 * *$ & 21,27 \\
GERM & 0,8354 n.s. & 24,46 \\
PRO & $16,2262 * *$ & 12,04 \\
\hline
\end{tabular}

Onde: Alt 1 é a altura aos 15 dias após o plantio (DAP) (cm); Alt 2 é a altura aos 21 DAP (cm); Alt 3 é altura aos 28 DAP $(\mathrm{cm})$; Alt 4 é a altura aos 35 DAP $(\mathrm{cm})$; Alt 5 é a altura aos 43 DAP $(\mathrm{cm})$; MSPA é a massa seca de parte aérea $(\mathrm{g}) ;$ MSR é a massa seca de raiz (g); PV é o peso das vagens(g); NV é o número de vagens por planta; NS é o número de sementes por vagem; GERM é a porcentagem de germinação; PRO é a concentração de prolina ( $\mathrm{mg} \mathrm{g}^{-1}$ ); $\mathrm{L}$ é lâmina de irrigação (\%ETc) e C.V. é o coeficiente de variação (\%). Os valores de $\mathrm{F}$ com *=significância a $5 \%$; ** significância a $1 \%$ e n.s.=não significativo.

A 

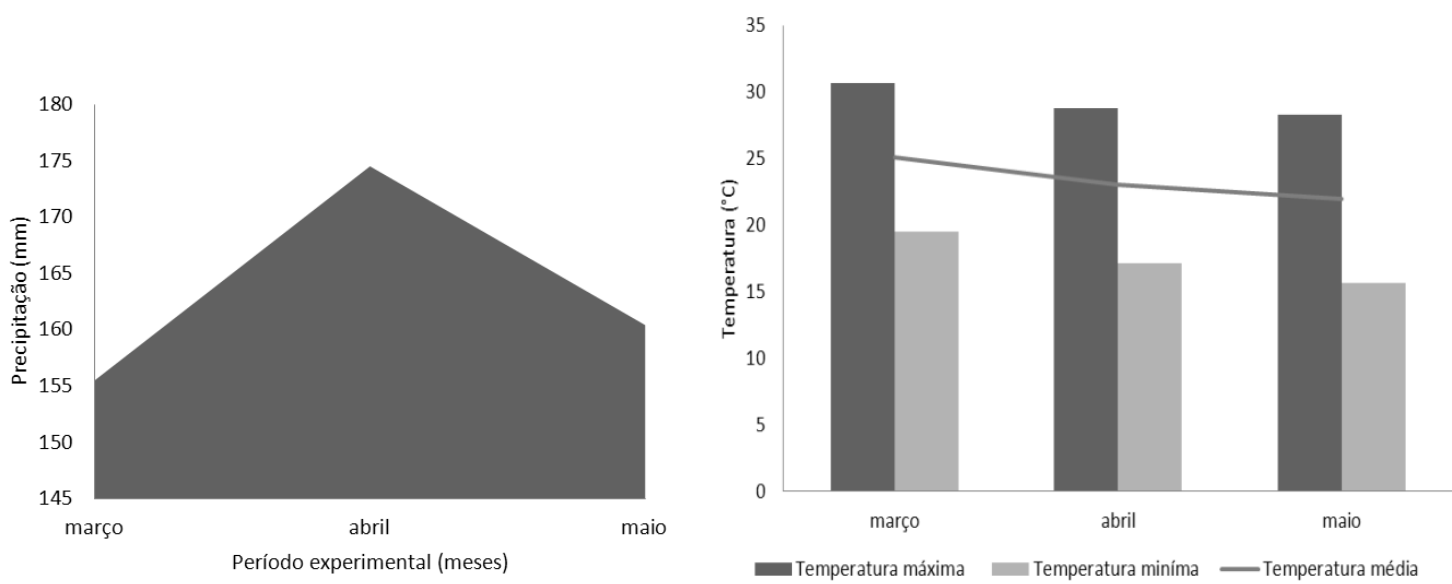

Figura 1. Dados climáticos do período do experimento: Precipitação (A) e Temperatura (B).

$\mathrm{Na}$ Tabela 2 observa-se que o peso das vagens foi maior para a lâmina de irrigação de $75 \%$ da evapotranspiração da cultura (ETc). O feijão respondeu positivamente à lâmina de irrigação com déficit hídrico, divergindo dos resultados obtidos por Nóbrega et al. (2001) os quais descrevem que o feijão é uma cultura sensível à disponibilidade hídrica e situações de déficit ou excesso hídrico podem comprometer seu desenvolvimento.

Estudos comprovam que a irrigação influencia decisivamente na produtividade do feijoeiro (TORRES et al., 2013). Para o feijãocaupi, as lâminas de irrigação de 108 a 130\% (290 a $325 \mathrm{~mm}$ ) da evapotranspiração de referência resultaram na maximização da produção da cultivar BRS Guariba. A obtenção da lâmina ótima de irrigação possibilitou o suprimento da demanda de água pela planta e a maximização da produção, resultando assim em utilização racional e economia de água (RAMOS et al., 2012).

Tabela 2. Peso das vagens (PV) por planta de feijão Pérola irrigado com diferentes lâminas de irrigação (25, $50,75,100,125$ e $150 \%$ ETc).

\begin{tabular}{ll}
\hline Lâmina de irrigação (\% ETc) & $\mathrm{PV}(\mathrm{g})$ \\
\hline 25 & $19,23 \mathrm{~B}$ \\
50 & $32,24 \mathrm{AB}$ \\
75 & $35,95 \mathrm{~A}$ \\
100 & $34,08 \mathrm{AB}$ \\
125 & $33,18 \mathrm{AB}$ \\
150 & $35,08 \mathrm{AB}$ \\
\hline
\end{tabular}

As letras maiúsculas comparam as médias, obtidas para a variável altura, pelo Teste Tukey.

Foi possível observar na Tabela 3 que a lâmina de irrigação de $75 \%$ ETc proporcionou maior número de grãos por vagens. Segundo Torres et al. (2013), o número de grãos por vagem apresenta correlação positiva com a lâmina de irrigação. Para esse estudo a lâmina de irrigação de $100 \%$ da evapotranspiração (ET) resultou no maior número de grãos por vagens.
Monteiro et al. (2010) verificou que as plantas de feijoeiro que receberam as maiores lâminas de irrigação por ciclo $(357,5$ e 406,2 mm) apresentaram os maiores resultados para as variáveis biométricas, como o número de grãos por vagem.

Tabela 3. Número de grãos (NG) por vagem em plantas de feijão Pérola irrigado com diferentes lâminas de irrigação $(25,50,75,100,125$ e $150 \%$ ETc).

\begin{tabular}{ll}
\hline Lâmina de irrigação (\% ETc) & NG \\
\hline 25 & $36,40 \mathrm{~B}$ \\
50 & $47,40 \mathrm{AB}$ \\
75 & $66,00 \mathrm{~A}$ \\
100 & $55,60 \mathrm{AB}$ \\
\hline
\end{tabular}




$\begin{array}{ll}125 & 44,00 \mathrm{~B} \\ 150 & 57,40 \mathrm{AB}\end{array}$

As letras maiúsculas comparam as médias, obtidas para a variável altura, pelo Teste Tukey.

A concentração de prolina nas folhas frescas (Tabela 4) aumentou na situação de menor disponibilidade hídrica, ou seja, na lâmina de irrigação de $25 \%$ ETc. O feijão apresenta uma necessidade hídrica de $300-500 \mathrm{~mm}$ por ciclo, sendo então sensível ao estresse hídrico (ANDRADE JÚNIOR et al., 2003). O aminoácido prolina é um marcador molecular de estresse hídrico, portanto em situações de baixa disponibilidade hídrica há uma tendência do aumento da sua concentração nas células vegetais (SANTOS et al., 2010). Para Monteiro (2014), a prolina é um bom indicador bioquímico e fisiológico de estresse hídrico, sendo o feijão uma planta sensível.

Tabela 4. Concentração de prolina nas folhas frescas de feijão Pérola irrigado com diferentes lâminas de irrigação $(25,50,75,100,125$ e $150 \%$ ETc).

\begin{tabular}{ll}
\hline Lâmina de irrigação (\% ETC) & Prolina $\left(\mathrm{mg} \mathrm{g}^{-1}\right)$ \\
\hline 25 & $1,7348 \mathrm{~A}$ \\
50 & $1,2717 \mathrm{~B}$ \\
75 & $1,1785 \mathrm{BC}$ \\
100 & $1,1969 \mathrm{BC}$ \\
125 & $0,9090 \mathrm{C}$ \\
150 & $0,9669 \mathrm{BC}$ \\
\hline
\end{tabular}

As letras maiúsculas comparam as médias, obtidas para a variável altura, pelo Teste Tukey.

De acordo com os resultados obtidos, concluiu-se que a lâmina de irrigação de $75 \%$ da evapotranspiração da cultura (ETc) é recomendada para a produção de grãos do feijoeiro no Oeste Paulista. A situação de déficit hídrico extremo (25\% $\mathrm{ETC})$ aumentou a concentração do osmorregulador prolina, como resposta ao estresse.

\section{REFERÊNCIAS}

ALLEN, R.G.; PEREIRA, L.S.; RAES, D.; SMITH, M. Crop evapotranspiration - Guidelines computing crop water requirements. FAO Irrigation and drainage paper 56, p.15, 1998.

ANDRADE JÚNIOR, A.S.; SANTOS, A.A.; SOBRINHOS, C.A.; BASTOS, E.A.; MELO, F.B.; VIANA, F.M.P.; FREIRE FILHO, F.R.; CARNEIRO, J.C.; ROCHA, M.M.; CARDOSO, M.J.; SILVA, P.H.S.; RIBEIRO, V.Q. Cultivo de feijão-caupi: irrigação. EMBRAPA, 2003. Disponível em:

<http://sistemasdeproducao.cnptia.embrapa.br/ FontesHTML/Feijao/FeijaoCaupi/irrigacao.htm>. Acesso em: 08 nov. 2013.

ANDRADE, A.R.S.; CRUZ, A.F.S.; CAVALCANTE, E.C.S.; ALBUQUERQUE, J.C.F.; SOUZA, W.M. Estimativa da evapotranspiração e dos coeficientes de cultura para diferentes fases de desenvolvimento da melancia. Revista Brasileira de Geografia Física, v.6, n.5, p.1417-1429, 2013.
BATES, L.S. et al. Rapid determination of free proline for water-stress studies, Plant and Soil, v.39, p.205-207, 1973.

BEZERRA, M.V.C.; SILVA, B.B.; BEZERRA, B.G.; BORGES, V.P.; OLIVEIRA, A.S. Evapotranspiração e coeficiente de cultura do algodoeiro irrigado a partir de imagens de sensores orbitais. Revista Ciência Agronômica, v.43, n.1, p.64-71, 2012. CARVALHO, J.J.; SAAD, J.C.C.; CUNHA, F.N.; SILVA, N.F.; TEIXEIRA, M.B. Manejo de irrigação no feijoeiro, cultivado em semeadura direta e convencional. Revista Brasileira de Agricultura Irrigada, v.8, n.1, p.52-63, 2014. CARVALHO, J.J.; SILVA, N.F.; ALVES, D.M; MORAIS, W.A.; CUNHA, F.N.; TEIXEIRA, M.B. Produtividade e teores de nutrientes em grãos de feijão sob diferentes manejo do solo e da irrigação. Revista Brasileira de Agricultura Irrigada v.8, n.3, p.296307, 2014.

CONAB. Acompanhamento da safra brasileira: grãos, v.1, n.3, p.1-72, 2013. EMBRAPA. Centro Nacional de Pesquisa de Solos (Rio de Janeiro, RJ). Sistema Brasileiro de Classificação de Solos. Brasília, DF: Embrapa Produção da Informação, 1999. 412 p. FARIAS, C. H. A.; SOUSA, K. S.; SILVA, I. F.; AGRA, R.V.; NETO, G. C. G.; Crescimento do sistema radicular de cana-de-açúcar submetida da lâminas de irrigação: modelo geoespacial e 
influências na produtividade da cultura. Revista Brasileira de Agricultura Irrigada, v.4, n.4, p.186196, 2010.

FOLEGATTI, M.V. Tabelas completas de irrigação. 2013 Disponível em :

<http://www.leb.esalq.usp.br/disciplinas/Folegat ti/leb1571/Tabelas\%20completas.pdf>. Acesso em: 08 nov. 2013.

GUBIANI, P.I.; REICHERT, J.M.; REINERT, D.J. Interação entre a disponibilidade de água e compactação do solo no crescimento e na produção do feijoeiro. Revista Brasileira de Ciência do Solo, n.38, p.765-773, 2014.

MACHADO NETO, N. B. et al. Water stress induced by mannitol and sodium chloride in soybean cultivars. Brazilian Archives Biology Technology, Curitiba, v.47, n.4, p.521-529, 2004. MONTEIRO, J.G.; CRUZ, F.J.R.; NARDIN, M.B.; SANTOS, D.M.M.; Crescimento e conteúdo de prolina em plântulas de guandu submetidas a estresse osmótico e à putrescina exógena.

Pesquisa Agropecuária Brasileira, v.49, n.1, p.1825, jan. 2014.

MONTEIRO, P.F.C.; FILHO, R.A.; MONTEIRO, R.O.C. Efeitos da irrigação e da adubação nitrogenada sobre variáveis agronômicas na cultura do feijão. Irriga, v.15, n.4, p.386-400, 2010.

NAKAGAWA, J. Testes de vigor baseados no desempenho das plântulas. In: KRZYZANOSKI, F.C.; VIEIRA, R.D.; FRANÇA NETO, J.B. (Ed.). Vigor de sementes: conceitos e testes. Londrina: ABRATES, 1999. p.2.1-2.24.

NÓBREGA, J.Q.; RAO, T.V.R.; NAPOLEÃO, E.M; BELTRÃO FILHO, J.F.

PAVANI, L.C.; LOPES, A.S.; PEREIRA, G.T. Desenvolvimento da cultura do feijoeiro submetida a dois sistemas de manejo de irrigação e de cultivo. Acta Scientiarum Agronomy, v.31, p.453-459, 2009.

RAMOS, H.M.M.; BASTOS, E.A.; ANDRADE

JÚNIOR, A.S.; MAROUELLI, W.A. Estratégias

ótimas de irrigação do feijão-caupi para a produção de grãos verdes. Pesquisa

Agropecuária Brasileira, v.47, n.4, p.576-583, 2012.

RIOS, G.F.A.; CARVALHO, L.G.; MAGINA, F.C.; NETO, P.C.; SILVA, B.M.; FRAGA, A.C. Consumo hídrico e coeficiente de cultura da mamoneira na microrregião de Lavras, Minas Gerais. Revista Brasileira de Engenharia Agrícola e Ambiental, v.15, n.12, p.1275-1282, 2011.

SANTOS, C.F.; LIMA, G.P.P.; MORGADO, L.B.

Tolerância e caracterização bioquímica em feijão submetido ao estresse hídrico na pré-floração.

Naturalia, v.33, p.34-44, 2010.

SILVA, J.C.; HELDWEIN, A.B.; RADONS, S.Z.;

MALDANER, I.C.; TRENTIN, G.; GRIMM, E.L.

Necessidade de irrigação para o feijoeiro na

região central do Rio Grande do Sul. Revista

Brasileira Engenharia Agrícola e Ambiental, v.15, n.10, p.1030-1036, 2011.

TORRES, J.L.R.; SANTANA, M.J.; PIZOLATO NETO, A.; VIEIRA, D.M.S. Produtividade de feijão sob lâminas de irrigação e coberturas de solo.

Bioscience Journal, v.29, n.4, p.833-841, 2013. VAN GENUCHTEN, M.T. A closed-form equation for predicting the hydraulic conductivity of unsaturated soils. Soil Science Society of America Journal, v.44, p.892-898, 1980.

Recebido para publicação em 25/09/2015

Revisado em 29/03/2016

Aceito em 13/04/2016 